\title{
Problems and Countermeasures of Information Security of Electric
}

\section{Power Enterprises in China}

\author{
Haixun Feng ${ }^{1, a}$, Yong Zang ${ }^{2, b}$ \\ ${ }^{1}$ State Grid Hebei Training Center, Shijiazhuang, Hebei, China, 050000 \\ ${ }^{2}$ State Grid Hebei Maintenance Branch, Shijiazhuang, Hebei, China, 050000 \\ ${ }^{\mathrm{a}}$ email, ${ }^{\mathrm{b}}$ email
}

Keywords: Electric Power Enterprises, Information Security, Information System

\begin{abstract}
Electric power enterprises have developed very rapid in recent years. The information construction of electric enterprises has also made great achievements. However, due to the constraints of time and experience, the information security of electric enterprises has some problems, which are the imperfections of regulations, awareness, technology and evaluation of information security. This paper analyzes the above problems, and puts forward the corresponding countermeasures in order to provide some references for the relevant researchers.
\end{abstract}

\section{Introduction}

Informatization is an inevitable trend of the development of social productive forces and production methods, and it is an important symbol of civilization construction in our country. Information construction can drive the improvement of enterprise management level and production efficiency, information resources as an important resource. Its importance is gradually being recognized by people. Electric power enterprises is a national production and economic development an important pillar in the backbone enterprises, geographical scope of power companies, covering the majority, business applications are cumbersome and complicated, staggered network topological structure, enterprise management and production application system intertwined. For the electric power enterprise, computer network and information system is core of the normal operation of enterprises, can be a reliable, stable and secure operation directly affect the stability of the whole power system, affecting the local economic development orderly. In view of the above all sorts of factors, formulate related operation of computer network and information system security management measures, to be the fundamental guarantee the robust enterprise operation of computer network and information system, electric power enterprises should pay attention to the basic problem. Each power enterprise has developed a security strategy, and implemented a part, while achieving the Internet Security access. Electric power enterprises to conscientiously implement the relevant laws and regulations of the state, and actively carry out the construction of security and risk assessment, to achieve the whole process of management, to ensure the safe and stable operation of electric power monitoring system. At the same time, the power enterprises actively carried out the evaluation and rectification work to improve the power information security system.

\section{Problems of Information Security of Electric Power Enterprises}

Electric power enterprise belongs to technology intensive industries, for production automation and intensive have higher requirements. In the construction of the network information, there are 
always a lot of problems. These problems have gradually become the hidden trouble of electric power enterprise network and information security.

Imperfection of Regulations of Information Security. Some power enterprises fail to update and revise the information security management system, regulation and system protection scheme in time according to the relevant laws and regulations. Part of the enterprise information security management system is not perfect. The responsibility system is not implemented and other issues. The power enterprise must carry on the division of the security level to the network of different safety grade. In the vertical direction, power enterprises need to realize the interconnection between real time monitoring systems. Between the various automation systems and low profile system are unidirectional data forwarding through the carrier, and part of the grass-roots power enterprises have not achieved the network data transmission, at the same time in the master station and the plant between stations did not achieve dual channel optical carrier. In the horizontal direction, the request can realize the mutual connection. It is difficult to realize the data sharing in the true sense, and the construction of the standard data interface is not on the interface between the system and the time system. Part of the power companies do not use the technology to set up a data scheduling network, did not meet the relevant safety requirements. There is no authentication encryption device between the upper and lower levels of scheduling.

Imperfection of Awareness of Information Security. With the information security status of the more significant, power companies for the training of information security also more and more, the scope of training is more and more widely, but because of the age of employees and engaged in different kinds of work, the employee of an electric power enterprise information security awareness imbalance is more and more obvious. Young workers and administrative staff awareness of information security is generally high, middle-aged and older workers, grass-roots front-line workers awareness of information security relatively low, resulting in uneven level of information security work. Part of the business of national industries and the information security policy requires understanding is not enough, did not establish a supervisory and control of power system security assessment mechanism; in important power industrial control system security assessment and classified protection, classification, filing, rectification and industry to seek a certain gap. Part of electric power enterprise network and information security personnel equipped with insufficient, has not set full-time information security administrator, network and information security related key position skill requirements is not clear, operation and maintenance ability deficiency and excessive dependence on manufacturers, propaganda and training work of failing to carry out. The information safety awareness is relatively weak and the training mode is single.

Imperfection of Technology of Information Security. The office computer still exists inside and outside the network mix. In accordance with the requirements of the China State Grid Corp, the unit office desktop computer has clearly required the isolation of internal and external network, that is, to eliminate a machine two network phenomenon. But to carry convenient notebook management has become the weak link of network isolation, probably because of a business trip, home of overtime and other reasons caused a laptop company intranet and Internet, intranet and other network mix of, for the electric power enterprise information security bring some hidden trouble. Internal and external network logic isolation strength is not enough. Because of the uncertainty of the wireless network coverage, wireless signal is likely to send to the perimeter of the company, leading to the company around can receive and access to the enterprise intranet, if the use of an ulterior motive, the enterprise network information security caused serious problems. As the power enterprise information construction earlier, which led to a lot of equipment and software have emerged a variety of security vulnerabilities, which have led to an increase in the degree of 
adverse safety consequences. Information network of its own in operating system, database and communication protocols exist security vulnerabilities and covert channel and other unsafe factors; storage medium damage caused by large amounts of information loss and residual information leaks, the computer equipment of electromagnetic radiation caused by the information leak. Network information using the unit fails to timely repair or preventing software vulnerabilities, using weak password settings, the lack of access control, an attacker using software default settings to attack, is a major cause of security incidents.

Imperfection of Evaluation of Information Security. Today, most of the computer network systems are generally only directed against a device, an application system, a level, a field of one or more combinations. Deployment of the security policy, monitoring and prevention technology for network and information system security management caused fundamental flaws, giving the attacker or malicious steal open a section of the road, making the network system and information system have the opportunity to active to expose the weak link. A robust computer network and information system should establish a complete set of security policy, monitoring and prevention technical measures from the perspective of three-dimensional to deal with all kinds of security threats. Electric power enterprises in the field of information security the most important is the data information, along with the advancing of information construction, the security of business information data has become top priority, at present electric power enterprise information security measures has been basically completed, but information system source code software companies rarely published to the electric power enterprises, resulting in system operation such as black box. The related information security risks are difficult to find.

\section{Countermeasures of Information Security of Electric Power Enterprises}

Improve Security Regulations. Enterprises should get a clear understanding of the network and information security is facing the grim situation, further strengthen organization and leadership, earnestly implement the relevant national laws and regulations, strict implementation of network and information security management relates to the responsible department, post, personnel and special funds, the network and information security safety position in the equally important with power production safety, into the assessment system of production safety, to ensure accountability in place. We should refer to the national and industry information security policies, standards, combined with the characteristics of its information system, to further improve the sound in line with its own information security measures and means; We should especially make the electric power marketing system and new energy power generation enterprises need more to strengthen the network security protection system construction. We should establish a computer network and information system security issues in the construction of the middle and long term construction standards. Establish a systematic, comprehensive, operable computer network and information security management system. These guidelines and systems provide a basis for effective security management of network and information systems.

Strengthen Security Awareness. Computer network and information system security management and technical measures in the final analysis is fundamental, management system is the guarantee, but system builders, designers, operation and maintenance, users et al factors is key of computer network and information security management systems. The role of various subjective consciousness's is not easily with the development of technology and management system raised how to strengthen computer networks and information systems in a variety of roles in the subjective consciousness to establish security view, take the initiative to comply with and enforce existing rule. It is a long-term task for the computer network and information system security management, at the 
same time also is the enterprise, the society will face the enterprise culture and social comprehensive quality of. ; to strengthen and standardize the work of the information systems system, standardizing the information security operation, improve the electric power enterprise staff information security skills and safety awareness; grass-roots power enterprises, local private power companies and outsourcing services team to further intensify efforts for the training of information security professionals, and enhance the ability of consciousness and information security information security. To carry out safety education and training should also pay attention to the level of safety knowledge, or at all levels of management personnel in charge of the director of the information security work, the focus is understanding and grasp of the overall strategy and target of enterprise information security, information security system, establishment and management system of safety management department making.

Upgrade Security Technology. The control of the computer virus outbreak will reduce the impact of the virus on the business. Many times, managers are able to find the problem after the outbreak of the virus, but it was too late. Therefore, we need to be able to find the root causes of the problem in the virus spread, to be able to effectively reduce the probability of the outbreak of the virus. Power enterprises should be combined with the progress of "Internet plus" plan of action and power system reform. They should strengthen the power control system of defense in depth, improve the safety of electric power industrial control terminal protection and enhance the power control ability of industrial control system security. In equipment selection and configuration shall be in conformity with the national relevant regulations, no use by the relevant state departments detection recognized the existence of loopholes and risks of system and equipment, for the operation of the system and equipment have been put into shall take effective protective measures for safety to ensure safe and stable operation of system and equipment. Electric power scientific research units and equipment manufacturers should strengthen technological innovation, actively participate in the formulation of the key equipment in the electric control system of information security standards and technical standards to pay attention to and strengthen the safety design of power control system.

Reinforce Security Evaluation. The evaluation of the security is the safety management of the soul. Network security is inseparable from the deployment of all kinds of security technology specific implementation and a variety of security products, but now appear on the market of security technology, security products is really let a person feel dazzling, difficult to choose, then we need to perform risk analysis, feasibility analysis, carries on the analysis to the electric power enterprises are facing the network risk, and analysis to solve a problem, or to the greatest extent reduce the risk of feasibility, on the benefits and the cost comparison, and analysis with which products can make power enterprises with their own minimum cost to meet the need of network security, also need to consider the safety and efficiency of the trade-off. For electric power enterprises, clear information system existing and potential risk, fully assess the threat and influence which may bring the risk. It will be the development of the security policy basis.

\section{Conclusion}

Information security is an integrated system, which involves not only the technical aspects but also the management of the above issues. With the continuous development of internet scale and technology, potential threats of information security will increase. Therefore, it is necessary to comprehensively and systematically analyze the problems of information security to ensure the system of electric enterprises stable and safe. 


\section{References}

[1] Wang Yingxin, Niu Dongxiao, ChinaManagement Informationization, Vol. 10 (2007) No 3, p.15-18

[2] Wang Shu, Computer Knowledge and Technology, Vol. 12 (2016) No 6, p.30-32

[3] Dang Lin, Public Communication of Science \& Technology, Vol. 4 (2012) No 8, p.22-24

[4] Li Mengxing, Chi Chengzhe, Wang Haiyan, Electric Power Information Technology, Vol. 8 (2010) No 12, p.36-38 